虑了 Doppler 展宽和 Stark 展宽对谱线轮 麻的影响,得到了与观测相符的结果. 对处 于爆发高潮后的激变变星 Z Cha，如果它的 Balmer 线仍是吸收线，我们预言了，在其交 食过程中不仅会出现吸收线，而且当交食的 轨道相角 $\phi=0^{\circ}$ 时, 吸收线中央会有发射 线核出现。

\section{$\Rightarrow$ 劣}

[1] Hessman, F. V., Ap. J., 300 (1986), 794.

[2] Kurucz, R. L., Ap. J. Suppl., 40 (1979), 1.

程富华

（中国科学技术大学天体物理中心,合成）

\title{
䍳酸的甲醇一一化学电离质谱及其气相酯化反应
}

化学电离 $(\mathrm{CI})$ 质谱是研究气相离子反 应的重要工具. 在离子源中，反应离子通常 与样品分子发生质子转移或电荷交换 反应, 使样品分子电离, 达到分子量测定的目的. Weinkam 和 Desiderio 等曾研究了气相离 子的溶剂解反应. 近年来人们开始注意到气 相离子可以发生许多经典有机化学反应. 我 们用甲醇作反应气，对不同类型的一元羒酸 进行了 $\mathrm{Cl}$ 质谱实验,观察到了羧酸的气相酯 化反应。

当离子源中甲醇的压力为 $0.5 \times 133.3 \mathrm{~Pa}$ 时,形成的反应离子主要为 $\left[\mathrm{CH}_{3} \mathrm{OH}\right] \mathrm{H}^{+}(m / z$ 33). 因此,䍳酸的甲醇 $-\mathrm{CI}$ 质谱图中显示的 离子为羒酸与质子化甲醇的气相反应产物. 在测定的 24 个样品中，有 22 个羧酸可以 发生醌化反应。它们的 CI 谱图中可以 观察到明显的甲酯化产物离子 $\left[\mathrm{RCO}_{2} \mathrm{CH}_{3}\right]$ $\mathrm{H}^{+}\left(\mathrm{MH}^{+}+14\right)$. 此外, 谱图中还出现高强度 的质子化分子和其失水产物, 以及样品分子
与反应离子的加成产物 $\mathrm{M}+\left[\mathrm{CH}_{3} \mathrm{OH}\right] \mathrm{H}^{+}$ $\left(\mathrm{MH}^{+}+32\right)$.

与经典溶液化学中酯化反应历程相似, 羧酸的气相酯化也是质子酸催化的过程. 当 样品分子的质子亲和势 (PA) 低于反应试剂 时,样品分子不能被质子化,因而不能发生酯 化. 如三氯乙酸和三第乙酸的 PA 值 $(736 \mathrm{~kJ}$ $\mathrm{mol}^{-1}$ ) 低于甲醇 (774kJ mol-1)，因此它们 既不能被甲醇质子化,也不能进行酯化反应.

羧酸的质子化部位也直接影响酯化反应 的进行. 只有当质子化发生在基年上, 从 而活化羰基时,才有可能发生酯化. 若质子 化发生在其他部位, 如氨基酸中的氨基,则不 能发生酯化反应, 只得到强度很高的质子化 分子。

柴文刚王光辉

(中国科学院化学研究所, 北京)

徐植霖 潘炣光

（中国中医研究院中药研究所，北京） 